\title{
Neutrosophic Parametrized Soft Set Theory and Its Decision Making Said Broumi ${ }^{a}$, Irfan Deli ${ }^{b}$ and Florentin Smarandache ${ }^{c}$ \\ ${ }^{a}$ Faculty of Arts and Humanities, Hay El Baraka Ben M'sik Casablanca B.P. 7951, Hassan II Mohammedia-Casablanca University, Morocco \\ ${ }^{\mathrm{b}}$ Muallim Rıfat Faculty of Education, Kilis 7 Aralık University, 79000 Kilis, Turkey \\ 'Department of Mathematics, University of New Mexico,705 Gurley Avenue, Gallup, NM 87301, USA
}

Keywords: Soft set, neutrosophic set, neutrosophic soft set, neutrosophic parameterized soft set, aggregation operator.

Abstract: In this work, we present definition of neutrosophic parameterized (NP) soft set and its operations. Then we define NP-aggregation operator to form NP-soft decision making method which allows constructing more efficient decision processes. We also dive an example which shows that they can be successfully applied to problem that contain indeterminacy.

\section{Introduction}

In 1999, Smarandache firstly proposed the theory of neutrosophic set (NS) [28], which is the generalization of the classical sets, conventional fuzzy set [30] and intuitionistic fuzzy set [5]. After Smarandache, neutrosophic sets has been successfully applied to many fields such as;control theory [1], databases [2,3], medical diagnosis problem [4], decision making problem [21], topology [22], and so on.

In 1999 a Russian researcher [27] firstly gave the soft set theory as a general mathematical tool for dealing with uncertainty and vagueness and how soft set theory is free from the parameterization inadequacy syndrome of fuzzy set theory, rough set theory, probability theory. Then, many interesting results of soft set theory have been studied on fuzzy soft sets [8,12,23], on intuitionistic fuzzy soft set theory [14,25], on possibility fuzzy soft set [7], on generalized fuzzy soft sets [26,29], on generalized intuitionistic fuzzy soft [6], on interval-valued intuitionistic fuzzy soft sets [20], on intuitionistic neutrosophic soft set [9], on generalized neutrosophic soft set [10], on fuzzy parameterized soft set theory [17,18], on fuzzy parameterized fuzzy soft set theory [13], on intuitionistic fuzzy parameterized soft set theory [15], on IFP-fuzzy soft set theory [16],on neutrosophic soft set [24].interval-valued neutrosophic soft set [11,19].

In this paper our main objective is to introduce the notion of neutrosophic parameterized soft set which is a generalization of fuzzy parameterized soft set and intuitionistic fuzzy parameterized soft set.The paper is structured as follows. In section 2, we first recall the necessary background on neutrosophic and soft set. In section 3, we give neutrosophic parameterized soft set theoryand their respective properties. In section 4 , we present a neutrosophic parameterized aggregation operator. In section 5, a neutrosophic parameterized decision methods is presented with example. Finally we conclude the paper.

\section{Preliminaries}

Throughout this paper, let $\mathrm{U}$ be a universal set and $\mathrm{E}$ be the set of all possible parameters under consideration with respect to $\mathrm{U}$, usually, parameters are attributes, characteristics, or properties of objects in $\mathrm{U}$.

We now recall some basic notions of neutrosophic set and soft set. For more details, the reader could refer to $[33,37]$. 
Definition 1.[37] Let $U$ be a universe of discourse then the neutrosophic set A is an object having the form

$$
\mathrm{A}=\left\{<\mathrm{x}: \mu_{\mathrm{A}(\mathrm{x})}, v_{\mathrm{A}(\mathrm{x})}, \omega_{\mathrm{A}(\mathrm{x})}>, \mathrm{x} \in \mathrm{U}\right\}
$$

where the functions $\mu, v, \omega: \mathrm{U} \rightarrow]^{-} 0,1^{+}[$define respectively the degree of membership, the degree of indeterminacy, and the degree of non-membership of the element $\mathrm{x} \in \mathrm{X}$ to the set $\mathrm{A}$ with the condition.

$$
{ }^{-} 0 \leq \mu_{\mathrm{A}(\mathrm{x})}+v_{\mathrm{A}(\mathrm{x})}+\omega_{\mathrm{A}(\mathrm{x})} \leq 3^{+}
$$

From philosophical point of view, the neutrosophic set takes the value from real standard or nonstandard subsets of $]-0,1+[$. So instead of $]-0,1+[$ we need to take the interval $[0,1]$ for technical applications, because $]-0,1+[$ will be difficult to apply in the real applications such as in scientific and engineering problems.

For two NS,

$$
A_{\mathrm{NS}}=\left\{<\mathrm{x}, \mu_{\mathrm{A}}(\mathrm{x}), \mathrm{v}_{\mathrm{A}}(\mathrm{x}), \omega_{\mathrm{A}}(\mathrm{x})>\mid \mathrm{x} \in \mathrm{X}\right\}
$$

And

$$
B_{\mathrm{NS}}=\left\{<\mathrm{x}, \mu_{\mathrm{B}}(\mathrm{x}), \mathrm{v}_{\mathrm{B}}(\mathrm{x}), \omega_{\mathrm{B}}(\mathrm{x})>\mid \mathrm{x} \in \mathrm{X}\right\}
$$

Then,

$$
\begin{aligned}
& A_{\mathrm{NS}} \subseteq B_{\mathrm{NS}} \text { if and only if } \\
& \mu_{\mathrm{A}}(\mathrm{x}) \leq \mu_{\mathrm{B}}(\mathrm{x}), v_{\mathrm{A}}(\mathrm{x}) \geq \mathrm{v}_{\mathrm{B}}(\mathrm{x}), \omega_{\mathrm{A}}(\mathrm{x}) \geq \omega_{\mathrm{B}}(\mathrm{x}) \\
& A_{\mathrm{NS}}=B_{\mathrm{NS}} \text { if and only if, } \\
& \mu_{\mathrm{A}}(\mathrm{x})=\mu_{\mathrm{B}}(\mathrm{x}), v_{\mathrm{A}}(\mathrm{x})=v_{\mathrm{B}}(\mathrm{x}), \omega_{\mathrm{A}}(\mathrm{x})=\omega_{\mathrm{B}}(\mathrm{x}) \text { for anyx } \in \mathrm{X} .
\end{aligned}
$$

The complement of $A_{\mathrm{NS}}$ is denoted by $A_{N S}^{o}$ and is defined by

$A_{N S}^{\circ}=\left\{<\mathrm{x}, \omega_{\mathrm{A}}(\mathrm{x}), 1-\mathrm{v}_{\mathrm{A}}(\mathrm{x}), \mu_{\mathrm{A}}(\mathrm{x}) \mid \mathrm{x} \in \mathrm{X}\right\}$

$\mathrm{A} \cap \mathrm{B}=\left\{<\mathrm{x}, \min \left\{\mu_{\mathrm{A}}(\mathrm{x}), \mu_{B}(\mathrm{x})\right\}, \max \left\{v_{\mathrm{A}}(\mathrm{x}), v_{B}(\mathrm{x})\right\}, \max \left\{\omega_{\mathrm{A}}(\mathrm{x}), \omega_{B}(\mathrm{x})\right\}>\mathrm{x} \in \mathrm{X}\right\}$

$A \cup B=\left\{<x, \max \left\{\mu_{A}(x), \mu_{B}(x)\right\}, \min \left\{v_{A}(x), v_{B}(x)\right\}, \min \left\{\omega_{A}(x), \omega_{B}(x)\right\}>: x \in X\right\}$

As an illustration, let us consider the following example.

Example 1.Assume that the universe of discourse $\mathrm{U}=\left\{\mathrm{x}_{1}, x_{2}, x_{3}, \mathrm{x}_{4}\right\}$. It may be further assumed that the values of $x_{1}, x_{2}, x_{3}$, and $x_{4}$ are in $[0,1]$ Then, $A$ is a neutrosophic set $(N S)$ of $U$, such that, 


$$
\left.\mathrm{A}=\left\{\left\langle\mathrm{x}_{1}, 0.4,0.6,0.5\right\rangle,\left\langle x_{2}, 0.3,0.4,0.7\right\rangle,\left\langle x_{3}, 0.4,0.4,0.6\right]\right\rangle,\left\langle\mathrm{x}_{4}, 0.5,0.4,0.8\right\rangle\right\}
$$

Definition 2.[33]

Let $\mathrm{U}$ be an initial universe set and $\mathrm{E}$ be a set of parameters. Let $\mathrm{P}(\mathrm{U})$ denotes the power set of $\mathrm{U}$. Consider a nonempty set $A, A \subset E$. A pair $(K, A)$ is called a soft set over $U$, where $K$ is a mapping given by $\mathrm{K}: \mathrm{A} \rightarrow \mathrm{P}(\mathrm{U})$.

As an illustration, let us consider the following example.

Example 2.Suppose that $\mathrm{U}$ is the set of houses under consideration, say $\mathrm{U}=\left\{h_{1}, h_{2}, h_{3}, h_{4}, h_{5}\right\}$. Let $\mathrm{E}$ be the set of some attributes of such houses, say $\mathrm{E}=\left\{e_{1}, e_{2}, e_{3}, e_{4}, e_{5}\right\}$, where $e_{1}, e_{2}, e_{3}, e_{4}, e_{5}$, stand for the attributes "beautiful", "costly", "in the green surroundings", "moderate" and technically, respectively. In this case, to define a soft set means to point out expensive houses, beautiful houses, and so on. For example, the soft set $(\mathrm{K}, \mathrm{A})$ that describes the "attractiveness of the houses" in the opinion of a buyer, says Thomas, and may be defined like this:

$\mathrm{A}=\left\{e_{1}, e_{2}, e_{3}, e_{4}, e_{5}\right\}$

$\mathrm{K}\left(e_{1}\right)=\left\{h_{2}, h_{3}, h_{5}\right\}, \mathrm{K}\left(e_{2}\right)=\left\{h_{2}, h_{4}\right\}, \mathrm{K}\left(e_{3}\right)=\left\{h_{1}\right\}, \mathrm{K}\left(e_{4}\right)=\mathrm{U}, \mathrm{K}\left(e_{5}\right)=\left\{h_{3}, h_{5}\right\}$.

\section{Neutrosophic Parameterized Soft Set Theory}

In this section, we define neutrosophic parameterized soft set and their operations.

Definition 3.1. Let $U$ be an initial universe, $P(U)$ be the power set of $U, E$ be a set of all parameters and $\mathrm{K}$ be a neutrosophic set over $\mathrm{E}$. Then a neutrosophic parameterized soft sets

$$
\begin{aligned}
& \Psi_{k}=\left\{\left(<x, \mu_{K}(\mathrm{x}), v_{K}(\mathrm{x}), \omega_{K}(\mathrm{x})>, \mathrm{f}_{K}(\mathrm{x})\right): \mathrm{x} \in \mathrm{E}\right\} \\
& \text { where } \mu_{K}: \mathrm{E} \rightarrow[0,1], v_{K}: \mathrm{E} \rightarrow[0,1], \omega_{K}: \mathrm{E} \rightarrow[0,1] \text { and } \mathrm{f}_{K}: \mathrm{E} \rightarrow \mathrm{P}(\mathrm{U}) \text { such that } \mathrm{f}_{K}(\mathrm{x})=\Phi \text { if } \\
& \mu_{K}(\mathrm{x})=0, v_{K}(\mathrm{x})=1 \text { and } \omega_{K}(\mathrm{x})=1 .
\end{aligned}
$$

Here, the function $\mu_{K, V K}$, and $\omega_{K}$ called membership function, indeterminacy function and nonmembership function of neutrosophic parameterized soft set (NP-soft set), respectively.

Example 3.2. Assume that $\left.U=\left\{\mathrm{u}_{1}, \mathrm{u}_{2}, \mathrm{u}_{3},\right\},\right\}$ is a universal set and $\mathrm{E}=\left\{\mathrm{x}_{1}, \mathrm{x}_{2}\right\}$ is a set of parameters.If

$$
\mathrm{K}=\left\{\left\langle\mathrm{x}_{1}, 0.2,0.3,0.4\right\rangle,\left\langle\mathrm{x}_{2}, 0.3,0.5,0.4\right\rangle\right\}
$$

and

$$
\mathrm{f}_{K}\left(\mathrm{x}_{1}\right)=\left\{\mathrm{u}_{2}, \mathrm{u}_{3}\right\}, \mathrm{f}_{K}\left(\mathrm{x}_{2}\right)=\mathrm{U}
$$

Then a neutrosophic parameterized soft set $\Psi_{k}$ is written by

$$
\Psi_{k}=\left\{\left(<\mathrm{x}_{1}, 0.2,0.3,0.4>,\left\{\mathrm{u}_{2}, \mathrm{u}_{3}\right\}\right),\left(<\mathrm{x}_{2}, 0.3,0.5,0.4>, \mathrm{U}\right)\right\}
$$


Definition 3.3.Let $\Psi_{k} \in$ NP-soft set. if $\mathrm{f}_{K}(\mathrm{x})=\mathrm{U}, \mu_{K}(\mathrm{x})=0, v_{K}(\mathrm{x})=1$ and $\omega_{K}(\mathrm{x})=1$ all $\mathrm{x} \in \mathrm{E}$. then $\Psi_{k}$ is called K-empty NP-soft set, denoted by $\Psi_{\Phi_{k}}$.

If $\mathrm{K}=\Phi$, then the K-emptyNP-soft set is called empty NP-soft set, denoted by $\Psi_{\mathbf{q}}$.

Definition 3.4. Let $\Psi_{k} \in \mathrm{NP}$-soft set. if $\mathrm{f}_{K}(\mathrm{x})=\mathrm{U}, \mu_{K}(\mathrm{x})=1, v_{K}(\mathrm{x})=0$ and $\omega_{K}(\mathrm{x})=0$ all $\mathrm{x} \in \mathrm{E}$. then $\Psi_{k}$ is called $\mathrm{K}$-universal NP-soft set, denoted by $\Psi_{\tilde{R}}$.

If $\mathrm{K}=\mathrm{E}$, then the K-universal NP-soft set is called universal NP-soft set, denoted by $\Psi_{\vec{E}}$.

Definition 3.5. $\Psi_{k}$ and $\Omega_{L}$ are two NP-soft set. Then, $\Psi_{k}$ is NP-subset of $\Omega_{L}$, denoted by $\Psi_{k} \subseteq \Omega_{L}$ if and only if $\mu_{K}(\mathrm{x}) \leq \mu_{L}(\mathrm{x}), v_{K}(\mathrm{x}) \geq v_{L}(\mathrm{x})$ and $\omega_{K}(\mathrm{x}) \geq \omega_{L}(\mathrm{x})$ and $f_{K}(\mathrm{x}) \subseteq \mathrm{g}_{L}(\mathrm{x})$ for all $\mathrm{x} \in \mathrm{E}$.

Definition 3.6. $\Psi_{k}$ and $\Omega_{L}$ are two NP-soft set. Then, $\Psi_{k}=\Omega_{L}$, if and only if $\Psi_{k} \sqsubseteq \Omega_{L}$ and $\Omega_{L} \sqsubseteq \Psi_{k}$ for all $\mathrm{x} \in \mathrm{E}$.

Definition 3.7. Let $\Psi_{k} \in \mathrm{NP}$-soft set. Then, the complement of $\Psi_{k}$, denoted by $\Psi_{K}^{c}$, is defined by $\Psi_{K}^{c}=\left\{\left(<x, \omega_{K}(x), v_{K}(x), \mu_{K}(x)>, f_{K^{c}}(x)\right): x \in E\right\}$

Where $\mathrm{f}_{K^{c}}(\mathrm{x})=\mathrm{U} \backslash \mathrm{f}_{K}(\mathrm{x})$

Definition 3.8.Let $\Psi_{k}$ and $\Omega_{L}$ are two NP-soft set. Then, union of $\Psi_{k}$ and $\Omega_{L}$, denoted by $\Psi_{k} \sqcup \Omega_{L}$ , is defined by

$\Psi_{k} \sqcup \Omega_{L}=\left\{\left(<x, \max \left\{\mu_{K}(\mathrm{x}), \mu_{L}(\mathrm{x})\right\}, \min \left\{v_{K}(\mathrm{x}), v_{L}(\mathrm{x})\right\}, \min \left\{\omega_{K}(\mathrm{x}), \omega_{L}(\mathrm{x})\right\}>, \mathrm{f}_{K \cup \mathrm{L}}(\mathrm{x})\right): \mathrm{x} \in \mathrm{E}\right\}$

wheref $_{K \cup \mathrm{L}}(\mathrm{x})=\mathrm{f}_{K}(\mathrm{x}) \cup \mathrm{f}_{L}(\mathrm{x})$.

Definition 3.9. Let $\Psi_{k}$ and $\Omega_{L}$ are two NP-soft set. Then, intersection of $\Psi_{K}$ and $\Omega_{L}$, denoted by $\Psi_{K} \sqcap \Omega_{L}$, is defined by

$\Psi_{k} \sqcap \Omega_{L}=$

$\left\{\left(<x, \min \left\{\mu_{K}(\mathrm{x}), \mu_{L}(\mathrm{x})\right\}, \max \left\{v_{K}(\mathrm{x}), v_{L}(\mathrm{x})\right\}, \max \left\{\omega_{K}(\mathrm{x}), \omega_{L}(\mathrm{x})\right\}>, \mathrm{f}_{K}(\mathrm{x}) \cap \mathrm{f}_{L}(\mathrm{x})\right): \mathrm{x} \in\right.$ E\}

wheref $_{K \cap \mathrm{L}}(\mathrm{x})=\mathrm{f}_{K}(\mathrm{x}) \cap \mathrm{f}_{L}(\mathrm{x})$.

Example 3.10.LetU $=\left\{\mathrm{u}_{1}, \mathrm{u}_{2}, \mathrm{u}_{3}, \mathrm{u}_{4}\right\}, \mathrm{E}=\left\{\mathrm{x}_{1}, \mathrm{x}_{2}, \mathrm{x}_{3}\right\}$. Then,

$\Psi_{K}=\left\{\left(<\mathrm{x}_{1}, 0.2,0.3,0.4>,\left\{\mathrm{u}_{1}, \mathrm{u}_{2}\right\}\right),\left(<\mathrm{x}_{2}, 0.3,0.5,0.4>,\left\{\mathrm{u}_{2}, \mathrm{u}_{3}\right\}\right)\right\}$

$\Omega_{L}=\left\{\left(<\mathrm{x}_{2}, 0.1,0.2,0.4>,\left\{\mathrm{u}_{3}, \mathrm{u}_{4}\right\}\right),\left(<\mathrm{x}_{3}, 0.5,0.20 .3>,\left\{\mathrm{u}_{3}\right\}\right)\right\}$

Then

$\Psi_{K} \sqcup \Omega_{L}=\left\{\left(<\mathrm{x}_{1}, 0.2,0.3,0.4>,\left\{\mathrm{u}_{1}, \mathrm{u}_{2}\right\}\right),\left(<\mathrm{x}_{2}, 0.3,0.2,0.4>,\left\{\mathrm{u}_{2}, \mathrm{u}_{3}, \mathrm{u}_{4}\right\}\right),\left(<\mathrm{x}_{3}, 0.5,0.20 .3>,\left\{\mathrm{u}_{3}\right\}\right)\right\}$

$\Psi_{K} \sqcap \Omega_{L}=\left\{\left(<\mathrm{x}_{2}, 0.1,0.5,0.4>,\left\{\mathrm{u}_{3}, \mathrm{u}_{4}\right\}\right)\right\}$.

$\Psi_{K}^{c}=\left\{\left(<\mathrm{x}_{1}, 0.4,0.3,0.2>,\left\{\mathrm{u}_{3}, \mathrm{u}_{4}\right\}\right),\left(<\mathrm{x}_{2}, 0.4,0.5,0.3>,\left\{\mathrm{u}_{1}, \mathrm{u}_{4}\right\}\right)\right\}$ 
Remark 3.11. $\Psi_{K} \sqsubseteq \Omega_{L}$ does not imply that every element of $\Psi_{K}$ an element of $\Omega_{L}$ as in the definition of classical subset. For example assume that $U=\left\{\mathrm{u}_{1}, \mathrm{u}_{2}, \mathrm{u}_{3}, \mathrm{u}_{4}\right\}$ is a universal set of objects and $\mathrm{E}=\left\{\mathrm{x}_{1}, \mathrm{x}_{2}, \mathrm{x}_{3}\right\}$ is a set of all parameters, if NP-soft sets $\Psi_{K}$ and $\Omega_{L}$ are defined as

$$
\begin{aligned}
& \Psi_{K}=\left\{\left(\left\langle\mathrm{x}_{1}, 0.2,0.3,0.4>,\left\{\mathrm{u}_{1}, \mathrm{u}_{2}\right\}\right),\left(<\mathrm{x}_{2}, 0.3,0.5,0.4>,\left\{\mathrm{u}_{2}\right\}\right)\right\}\right. \\
& \Omega_{L}=\left\{\left(<\mathrm{x}_{1}, 0.1,0.2,0.4>, \mathrm{U}\right),\left(<\mathrm{x}_{2}, 0.5,0.20 .3>,\left\{\mathrm{u}_{1}, \mathrm{u}_{4}\right\}\right)\right\}
\end{aligned}
$$

It can be seen that $\Psi_{K} \sqsubseteq \Omega_{L}$, but every element of ${ }_{K}$ not an element of $\Omega_{L}$

Proposition 3.12. Let $\Psi_{K}, \Omega_{L} \in{ }_{\mathrm{NP} \text {-soft set .Then }}$

$$
\begin{aligned}
& \Psi_{K} \sqsubseteq \Psi_{\hat{E}} \\
& \Psi_{\Phi} \sqsubseteq \Psi_{K} \\
& \Psi_{K} \sqsubseteq \Psi_{K}
\end{aligned}
$$

Proof .It is clear from Definition 3.3-3.5.

Proposition 3.13.Let $\Psi_{K}, \Omega_{L}$ and $\Upsilon_{M} \in$ NP-soft set, Then

$$
\begin{gathered}
\Psi_{K}=\Omega_{L} \text { and } \Omega_{L}=\Upsilon_{M} \Leftrightarrow \Psi_{K}=\Upsilon_{M} \\
\Psi_{K} \sqsubseteq \Omega_{L} \text { and } \Omega_{L} \sqsubseteq \Psi_{K} \Leftrightarrow \Psi_{K}=\Omega_{L} \\
\Psi_{K} \sqsubseteq \Omega_{L} \text { and } \Omega_{L} \sqsubseteq \Upsilon_{M} \Rightarrow \Psi_{K} \sqsubseteq \Upsilon_{M}
\end{gathered}
$$

Proof .It can be proved by Definition 3.3-3.5

$\left(\Psi_{K}^{c}\right)^{c}=\Psi_{k}$

$\Psi_{\Phi}^{\mathrm{c}}=\Psi_{\vec{E}}$

$\Psi_{\mathrm{E}}^{\mathrm{c}}=\Psi_{\mp}$

Proof. It is trial.

Proposition 3.15.Let $\Psi_{K}, \Omega_{L}$ and $\Upsilon_{M} \in$ NP-soft set, Then

$\Psi_{K} \sqcup \Psi_{K}=\Psi_{K}$

$\Psi_{K} \sqcup \Psi_{\tilde{\oiint}}=\Psi_{K}$

$\Psi_{K} \sqcup \Psi_{\vec{E}}=\Psi_{\vec{E}}$

$\Psi_{K} \sqcup \Omega_{L}=\Omega_{L} \sqcup \Psi_{K}$

$\left(\Psi_{K} \sqcup \Omega_{L}\right) \sqcup \Upsilon_{M}=\Psi_{K} \sqcup\left(\Omega_{L} \sqcup \Upsilon_{M}\right)$

Proof.It is clear 
Proposition 3.16.Let $\Psi_{K}, \Omega_{L}$ and $\Upsilon_{M} \in$ NP-soft set, Then

$\Psi_{K} \sqcap \Psi_{K}=\Psi_{K}$

$\Psi_{K} \sqcap \Psi_{\tilde{\Phi}}=\Psi_{\tilde{q}}$

$\Psi_{K} \sqcap \Psi_{\vec{E}}=\Psi_{K}$

$\Psi_{K} \sqcap \Omega_{L}=\Omega_{L} \sqcap \Psi_{K}$

$\left(\Psi_{K} \sqcap \Omega_{L}\right) \sqcap \Upsilon_{M}=\Psi_{K} \sqcap\left(\Omega_{L} \sqcap \Upsilon_{M}\right)$

Proof.It is clear

Proposition 3.17.Let $\Psi_{K}, \Omega_{L}$ and $\Upsilon_{M} \in$ NP-soft set, Then

$\Psi_{K} \sqcup\left(\Omega_{L} \sqcap \Upsilon_{M}\right)=\left(\Psi_{K} \sqcup \Omega_{L}\right) \sqcap\left(\Psi_{K} \sqcup \Upsilon_{M}\right)$

$\Psi_{K} \sqcap\left(\Omega_{L} \sqcup \Upsilon_{M}=\left(\Psi_{K} \sqcap \Omega_{L}\right) \sqcup\left(\Psi_{K} \sqcap \Upsilon_{M}\right)\right.$

Proof .It can be proved by definition 3.8 and 3.9

Proposition 3.18. Let $\Psi_{K}, \Omega_{L} \in$ NP-soft set, Then

$\left(\Psi_{K} \sqcup \Omega_{L}\right)^{c}=\Psi_{K}^{c} \sqcap \Omega_{L}^{c}$

$\left(\Psi_{K} \sqcap \Omega_{L}\right)^{c}=\Psi_{K}^{c} \sqcup \Omega_{L}^{c}$

Proof.It is clear.

Definition 3.19. Let $\Psi_{K}, \Omega_{L} \in$ NP-soft set, Then

OR-product of $\Psi_{K}$ and $\Omega_{L}$ denoted by $\Psi_{K} \underline{\vee} \Omega_{L}$, is defined as following

$\Psi_{K} \underline{v} \Omega_{L}=\left\{\left(<(\mathrm{x}, \mathrm{y}),\left(\max \left\{\mu_{K}(\mathrm{x}), \mu_{L}(\mathrm{y})\right\}, \min \left\{v_{K}(\mathrm{x}), v_{L}(\mathrm{x})\right\}, \min \left\{\omega_{K}(\mathrm{x}), \omega_{L}(\mathrm{y})\right\}>, \mathrm{f}_{K \cup \mathrm{L}}(\mathrm{x}, \mathrm{y})\right): \mathrm{x}, \mathrm{y}\right.\right.$ $\in \mathrm{E}\}$

wheref $_{K \cup \mathrm{L}}(\mathrm{x}, y)=\mathrm{f}_{K}(\mathrm{x}) \cup \mathrm{f}_{L}(\mathrm{y})$.

AND-product of $\Psi_{K}$ and $\Omega_{L}$ denoted by $\Psi_{K} \bar{\wedge} \Omega_{L}$ is defined as following

$\Psi_{K} \bar{\wedge} \Omega_{L}=\left\{\left(<(\mathrm{x}, \mathrm{y}),\left(\min \left\{\mu_{K}(\mathrm{x}), \mu_{L}(\mathrm{y})\right\}, \max \left\{v_{K}(\mathrm{x}), v_{L}(\mathrm{y})\right\}, \max \left\{\omega_{K}(\mathrm{x}), \omega_{L}(\mathrm{y})\right\}>, \mathrm{f}_{K \cap \mathrm{L}}(\mathrm{x}, \mathrm{y})\right): \mathrm{x}, \mathrm{y}\right.\right.$ $\in \mathrm{E}\}$

wheref $_{K \cap \mathrm{L}}(\mathrm{x}, y)=\mathrm{f}_{K}(\mathrm{x}) \cap \mathrm{f}_{L}(\mathrm{y})$.

Proposition 3.20.Let $\Psi_{K}, \Omega_{L}$ and $\Upsilon_{M} \in$ NP-soft set, Then

$\Psi_{K} \bar{\wedge} \Psi_{\Phi}=\Psi_{\Phi}$

$\left(\Psi_{K} \bar{\wedge} \Omega_{L}\right) \bar{\wedge} \Upsilon_{M}=\Psi_{K} \bar{\lambda}\left(\Omega_{L} \bar{\wedge} \Upsilon_{M}\right)$

$\left(\Psi_{K} \underline{\mathrm{V}} \Omega_{L}\right) \underline{\mathrm{V}} \Upsilon_{M}=\Psi_{K} \underline{\mathrm{V}}\left(\Omega_{L} \underline{\mathrm{V}} \Upsilon_{M}\right)$

Proof .It can be proved by definition 3.15 


\section{NP-aggregation operator}

In this section, we define NP-aggregation operator of an NP-soft set to construct a decisionmethod by which approximate functions of a soft set are combined to produce a single neutrosophic set that can be used to evaluate each alternative.

Definition 4.1. $\Psi_{K} \in$ NP-soft set. Then a NP-aggregation operatorof $\Psi_{K}$, denotedby $\Psi_{K}{ }^{a g g}$, is definedby

$\Psi_{K}^{a g g}=\left\{\quad\left(<\mathrm{u}, \mu_{K}{ }^{a g g}(u), v_{K}^{a g g}(u), \omega_{K}^{a g g}(\mathrm{u}): \mathrm{u} \in \mathrm{U} \quad\right\}\right.$

which is a neutrosophic set over $U$,

where

$$
\begin{aligned}
\mu_{K}^{\text {agg }}: \mathrm{U} \rightarrow[0,1] & \mu_{K}^{\text {agg }}(u)=\frac{1}{|\mathrm{U}|} \sum_{\substack{\mathrm{x} \in \mathrm{E} \\
\text { ueU }}} \mu_{K}(\mathrm{x}) \gamma_{\mathrm{f}_{\mathrm{K}(\mathrm{x})}}(\mathrm{u}), \\
v_{K}^{\text {agg }}:: \mathrm{U} \rightarrow[0,1] & v_{K}^{\text {agg }}(u)=\frac{1}{|\mathrm{U}|} \sum_{\substack{\mathrm{x} \in \mathrm{E} \\
\mathrm{u} \in \mathrm{U}}} v_{K} \quad(\mathrm{x}) \gamma_{\mathrm{f}_{\mathrm{K}(\mathrm{x})}}(\mathrm{u})
\end{aligned}
$$

and

$$
\omega_{K}{ }^{a g g}:: \mathrm{U} \rightarrow[0,1] \quad \omega_{K}{ }^{a g g}(u)=\frac{1}{|\mathrm{U}|} \sum_{\substack{\mathrm{x} \in \mathrm{E} \in \mathrm{U} \\,}} \omega_{K}(\mathrm{x}) \gamma_{\mathrm{f}_{\mathrm{K}(x)}}(\mathrm{u})
$$

And where

$$
\gamma_{\mathrm{f}_{\mathrm{K}(\mathrm{x})}}(\mathrm{u})= \begin{cases}1, & x \in \mathrm{f}_{\mathrm{K}}(\mathrm{x}) \\ 0, & \text { other wise }\end{cases}
$$

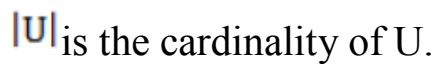

Definition 4.2Let $\Psi_{K} \in$ NP-soft set and $\Psi_{K}^{a g g}$ an aggregation neutrosophic parameterized soft set ,then a reduced fuzzy set of $\Psi_{K}{ }^{a g g}$ is a fuzzy set over U denoted by

$$
\Psi_{K}^{a g g}=\left\{\frac{\mu_{\Psi_{K f}}^{a g g}(u)}{u}: \mathrm{u} \in \mathrm{U}\right\}
$$

where $\mu_{\Psi_{K f}}^{\text {agg }}(u): \mathrm{U} \rightarrow[0,1]$ and $\mu_{\Psi_{K f}}^{\text {agg }(u)}{ }=\mu_{K}^{\text {agg }}(u)+v_{K}^{\text {agg }}(u)-\omega_{K}^{\text {agg }}(u)$.

\section{NP-Decision Methods}

Inspired by the decision making methods regard in [12-19].In this section, we also present NPdecision method to neutrosophic parameterized soft set. Based on definition 4.1 and 4.2 we construct an NP-decision making method by the following algorithm.

Now, we construct a NP-soft decision making method by the following algorithm to produce a decision fuzzy set from a crisp set of the alternatives.

According to the problem, decision maker

i. constructs a feasible Neutrosophic subsets K over the parameters set E,

ii. constructs a NP-soft set $\Psi_{K}$ over the alternatives set U,

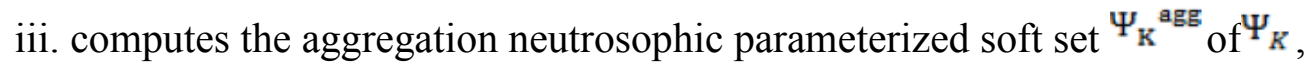

iv. computes the reduced fuzzy set ${ }_{\Psi_{\mathrm{Kf}} \mathrm{gg}_{(\mathrm{u})} \text { of }}{ }_{\mathrm{K}}^{\mathrm{agg}}$,

v. chooses the element of ${ }^{\mu_{\Psi_{\mathrm{Kf}}}{ }^{\mathrm{ggg}_{(\mathrm{u})}}}$

that has maximum membership degree.

Now, we can give an example for the NP-soft decision making method 
Example. Assume that a company wants to fill a position. There are four candidates who fill in a form in order to apply formally for the position. There is a decision maker (DM) that is from the department of human resources. He wants to interview the candidates, but it is very difficult to make it all of them. Therefore, by using the NP-soft decision making method, the number of candidates are reduced to a suitable one. Assume that the set of candidates $U=\left\{\mathrm{u}_{1}, \mathrm{u}_{2}, \mathrm{u}_{3}, \mathrm{u}_{4}\right\}$ which may be characterized by a set of parameters $E=\left\{x_{1}, x_{2}, x_{3}\right\}$ For $i=1,2,3$ the parameters $i$ stand for experience, computer knowledge and young age, respectively. Now, we can apply the method as follows:

Step i. Assume that DM constructs a feasible neutrosophic subsets K over the parameters set E as follows;

$$
\mathrm{K}=\left\{\left\langle\mathrm{x}_{1}, 0.2,0.3,0.4>,\left\langle\mathrm{x}_{2}, 0.3,0.2,0.4>,<\mathrm{x}_{3}, 0.5,0.20 .3>\right\}\right.\right.
$$

Step ii. DM constructs an NP-soft set $\Psi_{K}$ over the alternatives set U as follows;

$$
\Psi_{K}=\left\{\left(<\mathrm{x}_{1}, 0.2,0.3,0.4>,\left\{\mathrm{u}_{1}, \mathrm{u}_{2}\right\}\right),\left(<\mathrm{x}_{2}, 0.3,0.2,0.4>,\left\{\mathrm{u}_{2}, \mathrm{u}_{3}, \mathrm{u}_{4}\right\}\right),\left(<\mathrm{x}_{3}, 0.5,0.2,0.3>,\left\{\mathrm{u}_{3}\right\}\right)\right\}
$$

Step iii. DM computes the aggregation neutrosophic parameterized soft set ${ }^{\Psi_{\mathrm{K}}{ }^{\mathrm{agg}}}$ of $\Psi_{K}$ as follows; $\Psi_{K}{ }^{a g g}=\left\{<\mathrm{u}_{1}, 0.05,0.075,0.1>,<\mathrm{u}_{2}, 0.1,0.125,0.2>,<\mathrm{u}_{3}, 0.2,0.10 .175>,<\mathrm{u}_{4}, 0.125,0.050 .075>\right\}$

Step iv .computes the reduced fuzzy set $\mu_{\Psi_{K f}{ }^{a g g}(u)}$ of $\Psi_{K}{ }^{a g g}$ as follows;

$$
\begin{aligned}
& \mu_{\Psi_{K f}{ }^{a g g}\left(\mathrm{u}_{1}\right)}=0.025 \\
& \mu_{\Psi_{K f}{ }^{a g g}\left(\mathrm{u}_{2}\right)}=0.025 \\
& \mu_{\Psi_{K f}}^{a g g_{\left(\mathrm{u}_{\mathrm{s}}\right)}}=0.125 \\
& \mu_{\Psi_{K f}}^{a g g_{\left(\mathrm{u}_{4}\right)}}=0.1
\end{aligned}
$$

Step v .Finally, DM chooses $\mathrm{u}_{3}$ for the position from ${ }^{\mu_{\Psi_{f}}}{ }^{a g g}(u)$ since it has the maximum degree 0.125 among the others.

\section{Conclusion}

In this work, we have introduced the concept of neutrosophic parameterized soft set and studied some of its properties. The complement, union and intersection operations have been defined on the neutrosophic parameterized soft set. The definition of NP-aggregation operator is introduced with application of this operation in decision making problems. 


\section{References}

[1] S. Aggarwal, R. Biswas and A. Q. Ansari, Neutrosophic Modeling and Control, Computer and Communication Technology (2010) 718-723.

[2] M. Arora, R. Biswas and U.S. Pandy, Neutrosophic Relational Database Decomposition, International Journal of Advanced Computer Science and Applications, 2/ 8 (2011) 121-125.

[3] M. Arora and R. Biswas, Deployment of Neutrosophic Technology to Retrieve Answers for Queries Posed in Natural Language, in 3rdInternational Conference on Computer Science and Information Technology, (2010) 435-439.

[4] Ansari, Biswas, Aggarwal, Proposal for Applicability of Neutrosophic Set Theory in Medical AI, International Journal of Computer Applications, 27/5 (2011) 5-11.

[5] K. Atanassov. Intuitionistic Fuzzy Sets, Fuzzy Sets and Systems, 20 (1986) 87-96.

[6] K.V. Babitha and J. J. Sunil,”Generalized Intuitionistic Fuzzy Soft Sets and Its Applications “, Gen. Math. Notes, 7/ 2 (2011) 1-14.

[7] M. Bashir, A.R. Salleh, and S. Alkhazaleh, Possibility Intuitionistic Fuzzy Soft Set, Advances in Decision Sciences, doi:10.1155/2012/404325.

[8] M. Borah, T. J. Neog and D. K. Sut, A study on some operations of fuzzy soft sets, International Journal of Modern Engineering Research, $2 / 2$ (2012) 157-168.

[9] S. Broumi and F. Smarandache, "Intuitionistic Neutrosophic Soft Set", Journal of Information and Computing Science, 8/ 2 (2013) 130-140.

[10] S. Broumi, "Generalized Neutrosophic Soft Set", International Journal of Computer Science, Engineering and Information Technology, 3/2 (2013) 17-30.

[11] S. Broumi, I. Deli, and F. Smarandache, Relations on Interval Valued Neutrosophic Soft Sets, Journal of New Results in Science, 5 (2014) 1-20.

[12] N. Çağman, S. Enginoğlu, F. Çıtak Fuzzy Soft Set Theory and Its Applications. Iran J. Fuzzy Syst. 8(3) (2011) 137-147.

[13] N. Çağman, F Çıtak , S. Enginoğlu, Fuzzy parameterized fuzzy soft set theory and its applications, Turkish Journal of Fuzzy System 1/1 (2010) 21-35.

[14] N. Çağman, S. Karataş, Intuitionistic fuzzy soft set theory and its decision making, Journal of Intelligent and Fuzzy Systems DOI:10.3233/IFS-2012-0601.

[15] N. Çağman, I. Deli, Intuitionistic fuzzy parametrized soft set theory and its decision making, Submitted.

[16] N. Çağman, F. Karaaslan, IFP - fuzzy soft set theory and its applications, Submitted.

[17] N. Çağman, I. Deli, Product of FP-Soft Sets and its Applications, Hacettepe Journal of Mathematics and Statistics, 41/3 (2012) 365 - 374.

[18] N. Çağman, I. Deli, Means of FP-Soft Sets and its Applications, Hacettepe Journal of Mathematics and Statistics, 41/5 (2012) 615-625.

[19] I. Deli, Interval-valued neutrosophic soft sets and its decision making, submitted.

[20] Y. Jiang, Y. Tang, Q. Chen, H. Liu, J.Tang, "Interval-valued intuitionistic fuzzy soft sets and their properties", Computers and Mathematics with Applications, 60 (2010) 906-918.

[21] A. Kharal, A Neutrosophic Multicriteria Decision Making Method, New Mathematics and Natural Computation, Creighton University, USA, 2013.

[22] F.G. Lupiáñez, On neutrosophic topology, Kybernetes, 37/6 (2008) 797 - 800. 
[23] P. K. Maji, A. R. Roy and R. Biswas, Fuzzy soft sets, Journal of Fuzzy Mathematics, 9/3 (2001) 589-602.

[24] P. K. Maji, Neutrosophic Soft Set, Annals of Fuzzy Mathematics and Informatics, 5/ 1 (2013) 2287-623.

[25] P. K. Maji, R. Biswas and A. R. Roy, Intuitionistic fuzzy soft sets, The Journal of Fuzzy Mathematics, 9/3 (2001) 677-692.

[26] P. Majumdar, S. K. Samanta, Generalized Fuzzy Soft Sets, Computers and Mathematics with Applications, 59 (2010) 1425-1432.

[27] D. A. Molodtsov, Soft Set Theory First Result, Computers and Mathematics with Applications, 37 (1999) 19-31.

[28] F. Smarandache, “A Unifying Field in Logics. Neutrosophy: Neutrosophic Probability, Set and Logic". Rehoboth: American Research Press, 1999.

[29] H. L. Yang, Notes On Generalized Fuzzy Soft Sets, Journal of Mathematical Research and Exposition, $31 / 3$ (2011) 567-570.

[30] L. A. Zadeh, Fuzzy sets, Information and Control, 8 (1965) 338-353. 